\title{
PRÁCTICAS DE MANEJO, USOS Y VALORACIÓN DE TAXONES DE CACTACEAE EN EL NOROESTE DE CÓRDOBA, ARGENTINA
}

\author{
JULIETA KARINA TORRICO CHALABE ${ }^{1} \&$ CECILIA TRILLO ${ }^{1}$
}

\begin{abstract}
Summary: Torrico Chalabe, J. K. \& C. Trillo. 2015. Management practices, uses and valoration of taxa of Cactaceae in northwestern Córdoba, Argentina. Bonplandia 24(1): 5-22.

In the northwest of Córdoba, taxa of Cactaceae represent an important resource that contributes to the subsistence and daily life of local people, being winter particularly hard for people's life and animal production, and it is almost impossible to grow rain-fed crops all year round. The aim of this work was to recover and systematize local botanical knowledge, emphasizing the diversity of cactus taxa used, associated management practices, and valorization of these plants by residents of the study area. Here we report a list of 13 native and naturalized taxa, with their vernacular names and their uses. We recorded 12 types of uses and six management practices. Finally, we found that locals valued cacti as important or very important for their usefulness as a subsistence resource (forage and food) and for their ornamental value (aesthetic and economic). Therefore, the botanical knowledge of some people on these taxa represents useful future information for the entire population and for persons dealing with management and conservation plans of arid environments.
\end{abstract}

Key words: Cactaceae, Ethnobotany, management practices, uses, valoration.

Resumen: Torrico Chalabe, J. K. \& C. Trillo. 2015. Prácticas de manejo, usos y valoración de taxones de Cactaceae en el noroeste de Córdoba, Argentina. Bonplandia 24(1): 5-22.

En el noroeste de Córdoba, los taxones de Cactaceae representan un recurso importante que contribuye a la subsistencia y a la vida cotidiana de los pobladores locales, siendo el invierno particularmente duro para la vida de las personas y la producción de animales, y es casi imposible hacer cultivos anuales en secano. Se planteó como objetivo la recuperación y sistematización del conocimiento botánico local, poniendo énfasis en la diversidad de taxones utilizados, las prácticas de manejo asociadas y la valoración de estas plantas particulares por parte de los pobladores del área de estudio. Se realizó posteriormente un listado de 13 taxones nativos y naturalizados, con sus nombres vernáculos y sus usos. Se registraron 12 tipos de usos y 6 prácticas de manejo. Por último, se evidenció que los pobladores valoran a las cactáceas como importantes o muy importantes por su utilidad como recurso de subsistencia (forrajero y alimentario) y por su valor ornamental (estético y económico). Así, el conocimiento botánico de algunos pobladores sobre los taxones estudiados representa, para un futuro, información útil para toda la población y para los encargados de planes de manejo y conservación de ambientes áridos.

Palabras clave: Cactaceae, Etnobótanica, prácticas de manejo, usos, valoración.

${ }^{1}$ Cátedra de Diversidad Vegetal II, Etnobotánica, FCEFyN, UNC, Av.Vélez Sarsfield 299, 5000, Córdoba, Argentina. E-mail: jullieta_111@hotmail.com; ceciliatrillo1@gmail.com 


\section{Introducción}

La vida silvestre es un recurso importante para muchos pobladores del mundo, y de Latinoamérica en particular, utilizado con diversos propósitos, en especial, como fuente de alimento y de ingresos económicos (Altrichter, 2006; Cunningham, 2001). La utilización de recursos locales para satisfacer múltiples necesidades es orientada por el Conocimiento Ecológico Tradicional (CET) de los pobladores. Según Berkes (1999), este se define como: "un cuerpo acumulativo de conocimientos, prácticas, y creencias, que evolucionan por procesos adaptativos y se pasan a través de generaciones por transmisión cultural, sobre las relaciones de los seres vivos (incluidos los humanos) entre sí y con su ambiente". El CET es parte de la cultura local, en la cual los propios usuarios de los recursos son sus administradores, ellos mismos se identifican como miembros de la comunidad y conforman los sistemas tradicionales contextualizados a la situación local, usualmente no basados en la separación entre Naturaleza y Cultura (Berkes, 1999; Pochettino et al., 2008). En Etnobotánica, en relación con el empleo de los recursos vegetales, Pochettino et al. (2008) se refieren al Conocimiento Botánico Tradicional (CBT) como el conjunto de los saberes y creencias entorno a las plantas, las estrategias de selección y manipulación, las especificaciones sobre cuáles deben ser consideradas como recurso y cómo este debe ser gestionado en cada contexto local.

Existe un amplio rango de prácticas que se establecen con los vegetales considerados recursos; diferentes estudios arqueobotánicos y etnobotánicos demuestran que diferentes culturas establecen distintos sistemas de interacción con las plantas de su entorno, en muchos de los cuales la distinción entre sistemas de recolección y sistemas agrícolas resulta difícil (Caballero \& Cortés, 2001). Tales sistemas se basan en la manipulación de poblaciones de plantas silvestres con el fin de optimizar su aprovechamiento, a partir de prácticas de tolerancia, protección, control de la cantidad de nutrientes, humedad, luz, temperatura, y sobre la comunidad que las rodea: competidores, depredadores, polinizadores, dispersores, hasta llegar a la reproducción con el fin de asegurar la disponibilidad y productividad de recursos vegetales (Caballero \& Cortés, 2001; Casas, 2001). Las personas intervienen en el ambiente de distintas formas, mediante prácticas que afectan, en mayor o en menor medida, los paisajes en donde viven y desarrollan sus actividades cotidianas. Todas estas conductas relacionadas con las plantas, entonces, dejan como resultado modificaciones transitorias o permanentes en la biota original, que definen cada unidad de paisaje particular (Caballero \& Cortés, 2001; Casas, 2001).

Distintas especies de la familia botánica Cactaceae, muchas conocidas como "tunas", "pencas" y "cactus", constituyen recursos vegetales de interés etnobotánico en Latinoamérica. Las Cactaceae son un grupo muy particular de plantas que, como producto de su historia evolutiva, se caracterizan por la reducción de la superficie de transpiración y la retención de líquidos de manera muy eficiente en sus tejidos, lo que les permitió colonizar ambientes más áridos y vivir en condiciones de estrés hídrico (Kiesling \& Ferrari, 2005). El análisis de sus características permite diferenciar adaptaciones propias de $\mathrm{su}$ hábito: su morfofisiología expresa de manera eficaz la búsqueda y acumulación de agua, el acopio de reservas y la importancia de su reproducción vegetativa (Demaio \& Trevisson, 2006; Kiesling \& Ferrari, 2005; Kiesling et al., 2012). En México existen diversos estudios sobre la etnobotánica de estas plantas (Caballero \& Cortés, 2001; Caballero et al., 1998; Casas, 2001; Casas et al., 1987), que destacan una elevada valoración de las cactáceas debido a su capacidad de persistir en condiciones de extrema aridez, así como su importancia cultural, expresada en una mayor diversidad de usos y un mejor aprovechamiento como recurso.

En la Argentina, existen escasas publicaciones específicas sobre la utilidad y la valoración de las cactáceas (Hilgert \& Kiesling, 2002; Kiesling et al., 2012). Sin embargo, existen múltiples referencias etnobotánicas en el marco de estudios más amplios (Arenas \& Scarpa, 1998; Biurrun et al., 2007; Capparelli \& Raffino, 1997; Martínez-Crovetto, 1964; Roig \& Bárcena, 1983; Scarpa, 2007; entre los 
más destacados), en los que se relevan sus usos como alimenticias, forrajeras y colorantes. En Córdoba, en particular, se encontraron restos arqueológicos en el noroeste de la provincia, que sirven de evidencia de la utilización del "cardón" (Stetsonia coryne (Salm-Dyck) Britton \& Rose) como cercos vivos (Berberián, 1987; Pastor et al., 2012). Otros estudios mencionan el "quimilo" (Opuntia quimilo K. Schum.), y la "tunilla" (Opuntia sulphurea Gillies ex SalmDyck), utilizadas en algunas poblaciones rurales como alimento, forraje y para la obtención de tinturas de las cochinillas que viven sobre estas especies (Trillo et al., 2007; Zapata et al., 2005).

En la actualidad, una de las principales problemáticas ambientales de la provincia de Córdoba se debe a la expansión agrícola, que en los últimos 20 años implicó la deforestación de miles de hectáreas de bosque chaqueño, que representa la pérdida del $80 \%$ de los bosques originales, ahora ocupadas mayormente por cultivos de soja y por cultivos anuales (Zak et al., 2008). En el norte provincial, la pérdida de biodiversidad y la desaparición de los agricultores tradicionales se pueden relacionar con el avance de la agricultura industrial, que traería como consecuencia una erosión en el conocimiento botánico local, producto de miles de años de interacción entre las personas y su entorno vegetal. Asimismo, Arias Toledo et al. (2014) han indicado que el deterioro del conocimiento y la pérdida de usos de plantas nativas como medicinales se encuentran íntimamente relacionados con la pérdida de la biodiversidad local y la deforestación.
Considerando la escasez de estudios específicos sobre la importancia etnobotánica de las cactáceas en la vida de las poblaciones de las zonas áridas de Córdoba, y la poca cantidad de trabajos enfocados en los múltiples aspectos sobre la valoración, prácticas de manipulación y reproducción de especies silvestres, surgió el interés de explorar las relaciones entre los pobladores locales y las especies de Cactaceae en el ambiente semiárido del noroeste cordobés, donde estas plantas abundan y presentan una larga historia de uso. Como objetivo para este trabajo, se planteó la recuperación del conocimiento local, con énfasis en la diversidad de especies y variedades utilizadas, las prácticas de manejo asociadas y la valoración de este grupo particular de plantas por parte de los pobladores de diferentes localidades de los departamentos Cruz del Eje y Minas, provincia de Córdoba.

\section{Materiales y Métodos}

\section{Área de estudio}

El área de estudio se ubica en los departamentos de Cruz del Eje y Minas, noroeste de la provincia de Córdoba (Fig. 1.A). En términos fitogeográficos, el área corresponde a la Provincia Chaqueña, distritos del Chaco Occidental y Chaqueño Serrano (Cabido \& Zack, 1999; Cabrera, 1976; Luti et al., 1979). Cabido \& Zack (1999) dividen el

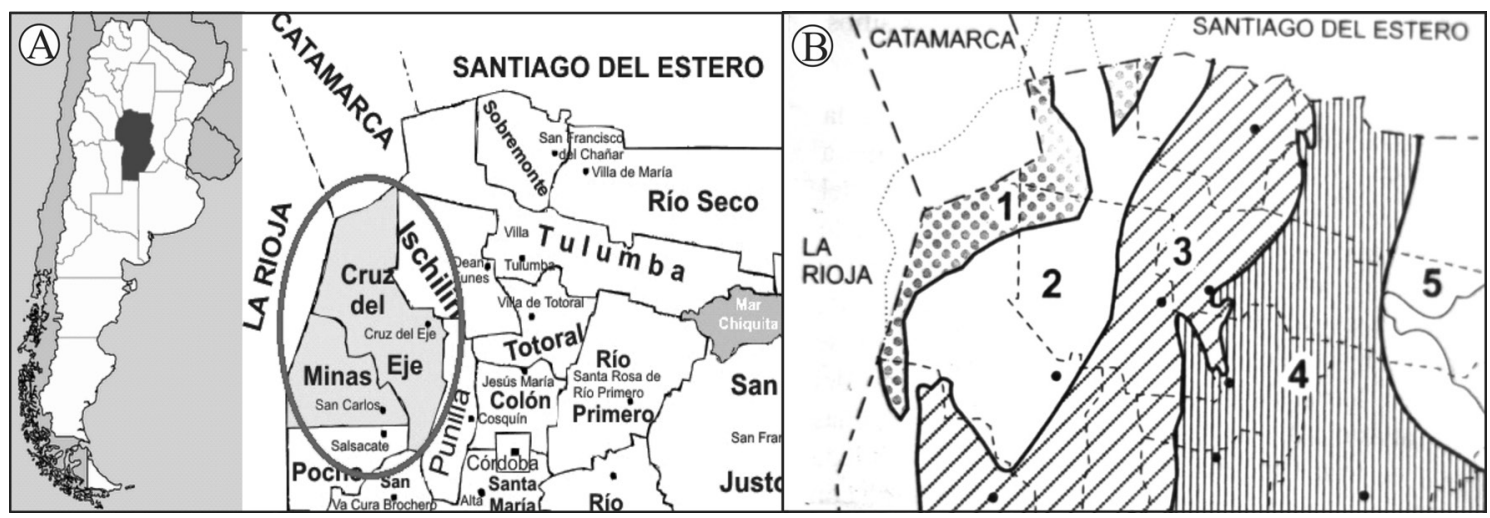

Fig. 1. A: Localización del área de estudio, departamentos de Minas y Cruz del Eje. B: Unidades fisiográficas del norte de la provincia de Córdoba. 1. Salinas Grandes, 2. Planicie Occidental, 3. Sistema Serrano, 4. Planicie Oriental, 5. Depresión Mar Chiquita (Cabido \& Zack, 1999). 
norte cordobés según las formas del relieve, en 5 unidades fisiográficas: Salinas Grandes, Planicie Occidental, Sistema Serrano, Planicie Oriental y Depresión de Mar Chiquita (Fig. 1. B). En este esquema, el noroeste de Córdoba corresponde a las Salinas Grandes, Planicie Occidental y Sistema Serrano (Cabido \& Zack, 1999), que forman parte principalmente del Chaco Árido (Cabrera, 1976), con precipitaciones entre 300 y $500 \mathrm{~mm}$ por año, con un máximo de lluvias en verano, que concentra el $70 \%$ de la precipitación total. Como consecuencia, el invierno es particularmente duro para la vida de las personas y de los animales, y es casi imposible hacer cultivos de secano. Este estudio se centra sólo en la Planicie Occidental, Salinas Grandes y Sistema Serrano.

La depresión de las Salinas Grandes tiene una altitud entre 150 y 300 m s.m., el suelo de este bolsón o playa es relativamente plano y salino, conformando característicos desiertos de sal con manchones de vegetación halófita; los márgenes, más elevados, presentan una vegetación transicional entre los matorrales de plantas halófitas y el bosque chaqueño xerófito (Cabido \& Zack, 1999). La vegetación halófita incluye dos unidades: 1) el matorral halófito bajo, o "jumeal", y 2) el matorral sub-halófito bajo, con "cardón” (Stetsonia coryne).

La Planicie Occidental, por su parte, tiene una altitud entre 250 y $450 \mathrm{~m}$ s.m. y se caracteriza por la ausencia de cursos de agua permanentes. Tiene un paisaje característico, aunque variado, en forma de bolsones. La vegetación original de esta llanura se componía de bosques, pero han sido modificados ampliamente por las actividades humanas. Presenta dos unidades de vegetación: 1) un bosque de "quebracho blanco" (Aspidosperma quebracho-blanco Schltd1.) con una fisonomía de bosque abierto y 2) un estrato herbáceo principalmente de gramíneas $\mathrm{C}_{4}$ perennes.

El Sistema Serrano, cuya altitud varía entre 700 y 1800 m s.m., presenta una cubierta vegetal que se distribuye en pisos o cinturones de vegetación según la altitud: bosques entre los 700 y 1200 m s.m.; matorrales entre los 900 y $1500 \mathrm{~m} \mathrm{s.m.;} \mathrm{y} \mathrm{pastizales} \mathrm{por} \mathrm{encima} \mathrm{de} \mathrm{los}$ 1500 m s.m. Comprende 3 unidades vegetación: 1) bosque serrano, con una fisonomía de bosque abierto a semi-cerrado, 2) matorrales serranos o "romerrillares", con el "romerillo" (Baccharis aliena (Spreng.) Joch.Müll.) como especie dominante, o 3) un "espinillar", donde domina el "espinillo" (Acacia caven (Molina) Molina). La mayor parte del área ha sido alterada de forma directa o indirecta por las actividades humanas, denominándose estas zonas como "vegetación cultural". Esta denominación incluye comunidades en las que la vegetación natural ha sufrido cambios significativos en su composición y estructura. Conforman sitios actualmente destinados a la agricultura, campos abandonados, lugares anteriormente ocupados por bosques y áreas en las cuales los incendios han producido una remoción significativa de la biomasa; siempre teniendo en cuenta que el tiempo no ha sido suficiente para el desarrollo de matorrales de sustitución o reemplazo (Cabido \& Pacha, 2002; Cabido \& Zack, 1999).

La densidad poblacional del Chaco Árido es baja, un promedio de 1,4 habitantes por $\mathrm{km}^{2}$ en ciudades y pueblos (entre el 60 y el $70 \%$ de la población) y $0,5-0,7$ habitantes $/ \mathrm{km}^{2}$ en áreas rurales. La rentabilidad general de la región es baja, debido al estado de los recursos naturales, los esquemas de producción y manejo, el tipo de productos de bajo valor obtenidos, y el sistema de comercialización existente (Basco et al., 1980).

En el Departamento Minas la totalidad de la población es rural. Las tres localidades estudiadas, La Playa, Guasapampa y Piedrita Blanca, pertenecen a la Pedanía de Guasapampa, la que posee una densidad poblacional de 1,3 habitantes por $\mathrm{km}^{2}$, y se encuentra inmersa en el denominado "Valle de Guasapampa". El Departamento de Cruz del Eje tiene una densidad poblacional de 8,83 habitantes por $\mathrm{km}^{2}$, distribuida en una población urbana de 37.760 personas y una población rural de 20.999 habitantes. Las seis localidades estudiadas fueron Cruz del Eje, Villa de Soto, Serrezuela, San Marcos Sierra, Tuclame y La Batea.

Se visitaron las localidades y zonas aledañas de San Marcos Sierra, Guasapampa y La Playa (Sistema Serrano), Tuclame, Cruz del Eje y Villa de Soto (Planicie Occidental) y Serrezuela, La Batea y Piedritas Blancas (Salinas Grandes) (Fig. 2). 


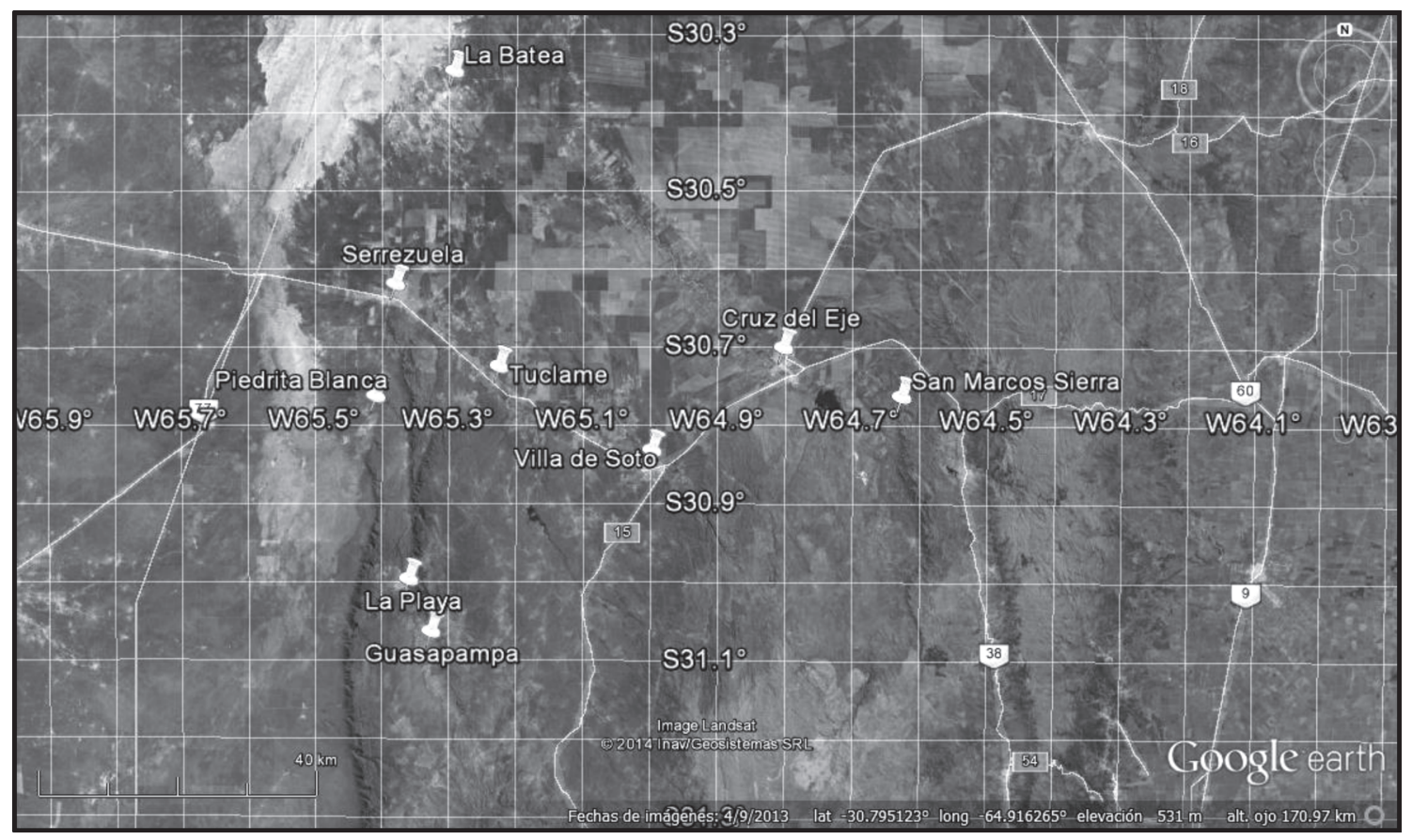

Fig. 2. Ubicación del área de estudio, con identificación de las localidades visitadas: La Batea, Serrezuela y Piedrita Blanca (Salinas Grandes), Tuclame, Villa de Soto y Cruz del Eje (Planicie Occidental) y Guasapampa, La Playa y San Marcos Sierra (Sistema Serrano).

Bergamin (1992) ubica la zona de estudio en la Argentina "extrapampeana", con concentraciones de producciones agropecuarias regionales, típicas de climas áridos y semiáridos, no destinadas al mercado de exportación. En la zona del Chaco árido, la actividad consiste básicamente en la producción de carbón, leña, cabras y vacunos. Esta región representa una economía complementaria de la metrópolis urbana, con una estructura dependiente de la demanda, economía monoexportadora con capacidad de negociación escasa o nula, explotación de mano de obra barata y bajos niveles de vida. El pequeño productor campesino posee una unidad agropecuaria de producción y consumo, bajo distintas formas de tenencia, que por la escasez de recursos naturales o de capital se basa principalmente en el grupo familiar. Si la unidad agropecuaria no permite cubrir las necesidades, es posible que un miembro de la familia emigre o se generen ingresos extraprediales, mediante la contratación de la mano de obra de algún miembro de la familia
(Bergamin, 1992; Trillo, 2010).

Cáceres et al. (2006) caracterizan a los campesinos del noroeste de la provincia de Córdoba como "unidades campesinas que pueden ser entendidas como un ámbito de actividad múltiple que no se restringe exclusivamente al campo productivo". En el presente trabajo, estos campesinos serán denominados "criollos" (Trillo, 2010). La estructura de este tipo de sistema presenta una mayor complejidad funcional ya que, además de producir bienes de mercado, cumplen también la función de vivienda familiar única. A menudo, estas unidades campesinas constituyen la principal fuente de provisión de alimentos para el grupo doméstico. En este tipo de explotación familiar, las actividades productivas están indisolublemente unidas a la esfera doméstica; por este motivo, con frecuencia se refiere a las unidades campesinas como unidades de "producción-viviendaconsumo".

La zona del noroeste cordobés, en particular, en la que se centra este estudio, puede ser 
enmarcada en dos situaciones sociales, una población rural con producción ganadera como principal producto para autosustento y para ventas menores, y una población urbana que vive del turismo, productos artesanales y otros (Cáceres et al., 2006).

\section{Metodología}

La metodología inicial de prospección y recopilación de datos fue la observación participante (Padua, 1994). Se efectuaron unas primeras visitas con entrevistas abiertas y caminatas por las zonas del campo y aledaños, con preguntas generales (Cotton, 1996) sobre usos de las cactáceas, especies que conocen, prácticas que realizan en sus campos, y se confeccionó un álbum de fotografías de las especies que surgieron de esta primera aproximación.

Se llevaron a cabo entrevistas semiestructuradas aplicando una metodología ad hoc (Aldrige \& Lavine, 2003; Bernard, 1995; Padua, 1994). En principio se realizaron preguntas abiertas relativas al conocimiento de las especies de Cactaceae, a los nombres regionales o comunes otorgados por los pobladores locales, el uso adjudicado y las prácticas de manejo que realizan o conocen. Luego, se hicieron preguntas cerradas a partir de listas pre-confeccionadas observando con los entrevistados el álbum fotográfico, el cual contaba con un par de fotografías para cada una de las especies; para indagar sobre el reconocimiento de las especies, sus usos y si realizan algún/os tipo/s de manejo/s sobre alguna de las especies (Bernard, 1995).

Se realizó una muestra no aleatoria y sólo se incluyeron informantes clave: especialistas o expertos nativos con un profundo conocimiento de un aspecto particular de la cultura local (Costa-Neto, 2002); en este caso, de las especies de Cactaceae. El método de muestreo fue el de bola de nieve (Aguilera et al., 2003), que puede definirse como una técnica de investigación en la que el primer sujeto que se contacta da al investigador el nombre de otro sujeto, que a su vez proporciona el nombre de un tercero, y así sucesivamente, hasta que se entrevistaron todos los posibles informantes clave. Estas personas se identificaron como informantes clave dado que fueron las que los pobladores en estudio proponen como aquellas que presentan un mayor conocimiento sobre la temática de la investigación. Esta estrategia puede verse como una respuesta para resolver los problemas asociados con el muestreo de poblaciones aisladas (Aguilera et al., 2003).

Con cada informante clave se realizó una caminata en la zona de influencia doméstica y peridoméstica, a los fines de corroborar las especies Cactaceae nombradas por los informantes.

Las especies, subespecies y variedades de Cactaceae relevadas (13 taxones en total) fueron registradas de manera fotográfica. $\mathrm{Su}$ identificación fuerealizada a partir de bibliografía específica (Demaio \& Trevisson, 2006; Kiesling \& Ferrari, 2005), con la información disponible en bases de datos (Instituto de Botánica Darwinion, 2015 y Flora Argentina, 2015), y consultas al Dr. Pablo Demaio perteneciente al Museo Botánico de la Universidad Nacional de Córdoba (CORD), quien además facilitó la revisión de ejemplares tipo disponibles en el Museo y la correcta identificación de cada especie del álbum fotográfico.

\section{Análisis de los datos}

En referencia a las prácticas de manejo, forma de manipulación o de interacción con las personas y las plantas, es posible reconocer diferentes patrones, según distintos estudios etnobotánicos (Caballero \& Cortés, 2001; Casas, 2001; Casas et al., 1987, 1996, 2007). En esta contribución se utilizó la división y conceptualización de prácticas de manejo de Casas (2001):

Manejo in situ: interacciones que se llevan a cabo en los espacios donde se hallan las poblaciones de plantas silvestres:

- Recolección: cosecha de plantas silvestres y arvenses, o sus partes útiles; no incluye un manejo de la vegetación y su impacto sobre ésta suele ser mínimo.

- Tolerancia: prácticas dirigidas a mantener dentro de ambientes antropogénicos, plantas útiles que existían antes de que el ambiente fuera transformado por las personas. 
- Fomento o inducción: estrategias dirigidas a aumentar la densidad de población de especies útiles. Puedellevarse a cabo mediante quemas, talas o por siembra de semillas y propagación de estructuras reproductivas vegetativas dentro de las mismas áreas de las poblaciones silvestres o arvenses.

- Protección: cuidados como la eliminación de competidores y depredadores, aplicación de fertilizantes, podas, protección contra heladas, entre otros, con el fin de salvaguardar algunas plantas silvestres y arvenses de valor especial. Estas actividades logran aumentar el número de individuos en las poblaciones.

Manejo ex situ: interacciones que suceden fuera de los espacios donde se encuentran las poblaciones de plantas silvestres, es decir, en ambientes creados y controlados por los seres humanos. Este manejo usualmente ocurre con las plantas domesticadas, pero también es posible encontrarlo con plantas silvestres y arvenses.

- Siembra y Plantación: propagación artificial de las estructuras reproductivas sexuales o vegetativas extraídas de poblaciones de plantas silvestres o arvenses.

- Trasplante: remoción del individuo completo tomado de poblaciones silvestres o arvenses.

A partir de este esquema, se analizó cuáles eran las prácticas locales más realizadas, sobre qué especies, de qué manera y con qué motivos generales, según el discurso de los entrevistados.

Para determinar la valoración que los entrevistados le atribuyen a las especies de Cactaceae se confeccionaron preguntas para medición de actitudes tipo Lickert y preguntas abiertas, con el fin de dejar al entrevistado expresar el porqué de su opinión. Es un tipo de escala aditiva que corresponde a un nivel de medición ordinal, consistente en una serie de ítems ante los cuales se solicita la reacción del sujeto, las respuestas son solicitadas en términos de grados, acuerdo o desacuerdo, y es una escala centrada en el sujeto. En este tipo de escalas, el supuesto subyacente es que la variación en las respuestas será debida a diferencias individuales entre los sujetos investigados (Padua, 1994).

Se realizó una tabla con el listado de las especies tratadas en orden alfabético, con su nombre científico, los nombres comunes que hayan mencionado los encuestados, los usos que nombraron y describieron (Tabla 1).

\section{Procedimiento Estadístico}

Se realizaron histogramas de frecuencia relativa de cantidad de menciones por especie y de frecuencias absolutas de cantidad de usos por especie registrada. Se tomó como criterio inicial la clasificación de 24 usos de Braier que se utilizan en Secretaría de Ambiente y Desarrollo Sustentable (SAyDS); Secretaría de Agricultura, Ganadería, Pesca y Alimentos (SAGPyA) y en la Organización de las Naciones Unidas para la Alimentación y la Agricultura (FAO) (Morello et al., 2009). En este trabajo, los usos se clasificaron en 12 tipos: forrajero, alimentario, construcción de cercos, de artesanías, ornamental (que incluye su uso comercial), recurso maderero, predictivo del clima, medicinal, tintóreo, fijación de pintura, purificación de agua y cosmético.

Con respecto a las prácticas de manejo, se realizó un histograma de frecuencias absolutas de la cantidad de menciones por práctica, considerando que por cada especie podían mencionar más de una práctica de manejo, teniendo un $\mathrm{n}=225$ menciones en total, entre las 19 encuestas realizadas. Y por cada práctica también se hizo un histograma de frecuencias absolutas de la cantidad de menciones por especie.

La valoración de las cactáceas se determinó con la medición de la moda, específico para el análisis del nivel nominal de datos cualitativos (Padua, 1994).

\section{Resultados}

Este trabajo permitió recoger datos de campo sobre las unidades fisiográficas chaqueñas de Planicie Occidental, Salinas Grandes y Sistema Serrano del noroeste de Córdoba, en relación con la valoración, las prácticas de manejo y el uso de especies silvestres y cultivadas de Cactaceae, que forman parte de la vida local de los pobladores entrevistados.

A partir de encuentros con los pobladores, caminatas de reconocimiento, muestreo y 


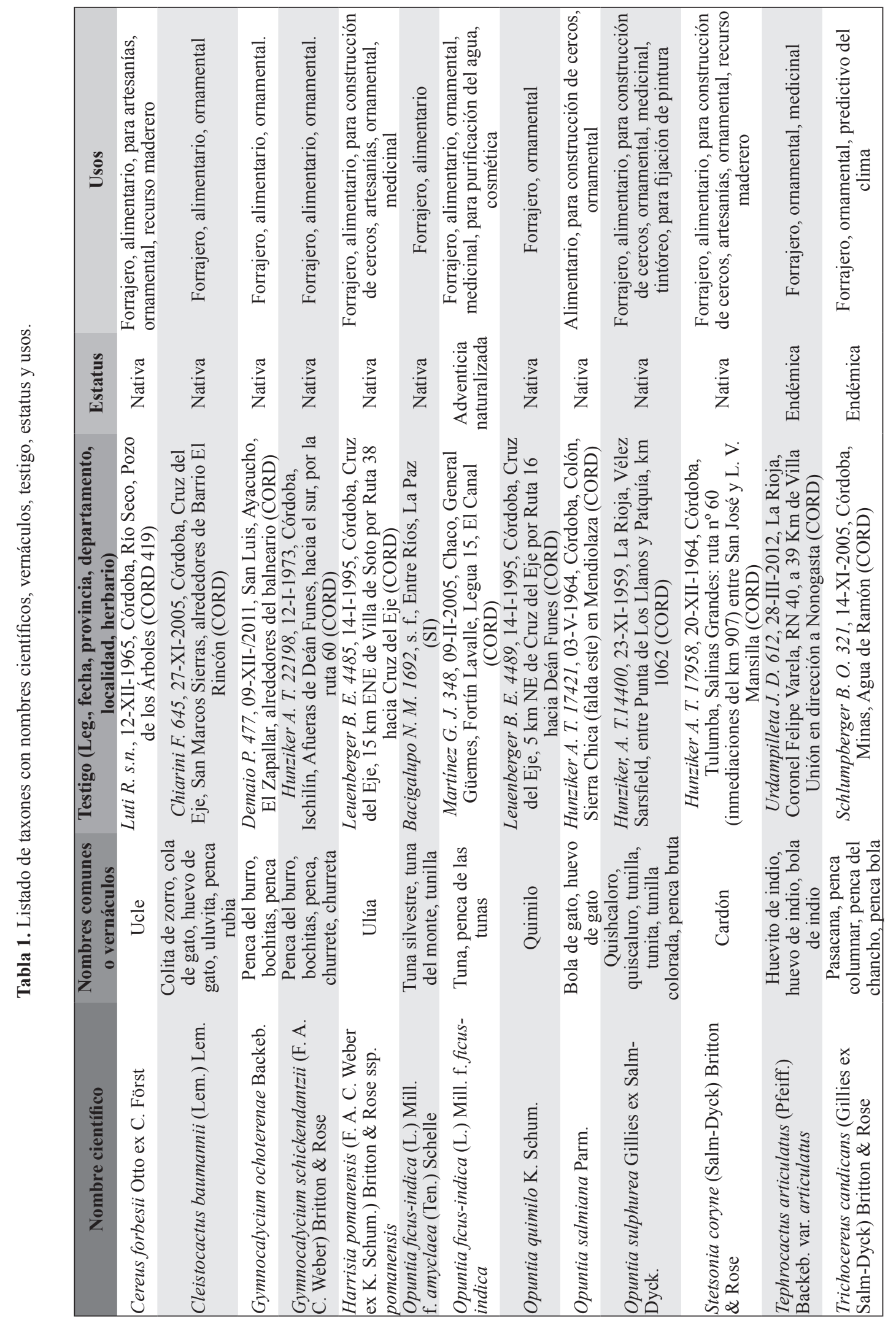


entrevistas semiestructuradas se sistematizó la información correspondiente a 10 especies nativas y 2 variedades de una especie naturalizada (Tabla 1), con sus nombres comunes, sus usos y manejos, que forman parte del conocimiento tradicional de los pobladores. De los 13 taxones mencionados, solamente Opuntia elata Salm-Dyck, con nombre común "penca bruta, tunilla o penca", con usos forrajero y alimentario, no cuenta con un voucher presente en el Museo Botánico de Córdoba, razón por la cual no se incluyó en la Tabla 1 pero es mencionada en este apartado.

Se registraron un total de 12 tipos de usos y 6 prácticas de manejo.

Se realizó un histograma de frecuencias relativas de la cantidad de menciones para cada especie (Fig. 3), teniendo un $n=19$ menciones en total para cada lista de las 19 encuestas. De manera general se puede observar que la especie más nombrada es la "tuna" (Opuntia ficus-indica (L.) Mill.), a la que siguen el "huevo de indio" (Tephrocactus articulatus (Pfeiff.) Backeb.), el "quishcaloro" (Opuntia sulphurea), el "cardón” (Stetsonia coryne), el "ucle" (Cereus forbesii Otto ex C.F. Först.), dentro de las 5 especies más mencionadas, y la "colita de zorro" (Cleistocactus baumannii
(Lem.) Lem.), la "pasacana" (Trichocereus candicans (Gillies ex Salm-Dyck) Britton \& Rose) y la "ulúa" (Harrisia pomanensis (F.A.C. Weber ex K. Schum.) Britton \& Rose), que se encuentran entre las que fueron mencionadas por más de la mitad de las personas. Cabe destacar que son las especies nativas con más usos y/o las más abundantes. También es importante resaltar que, a pesar de las diferencias registradas en la cantidad de menciones, todas las especies fueron nombradas por lo menos una vez.

Con respecto a los usos, se realizó un histograma de frecuencias absolutas de la cantidad de usos por especie (Fig. 4). Se registraron 12 tipos de usos, entre las 19 encuestas. Todas las especies de cactáceas que forman parte de este estudio tienen al menos una referencia de uso por parte de los pobladores. Las especies que presentaron más menciones de usos fueron: "quishcaloro" (Opuntia sulphurea), 7 usos; "cardón" (Stetsonia coryne), 6 usos; "tuna" (Opuntia ficus-indica f. ficus-indica), 6 usos; "ulúa" (Harrisia pomanensis), 6 usos y el "ucle" (Cereus forbesii), con 5 usos. Para las especies restantes, sólo se registraron 3 ó 2 usos por especie.

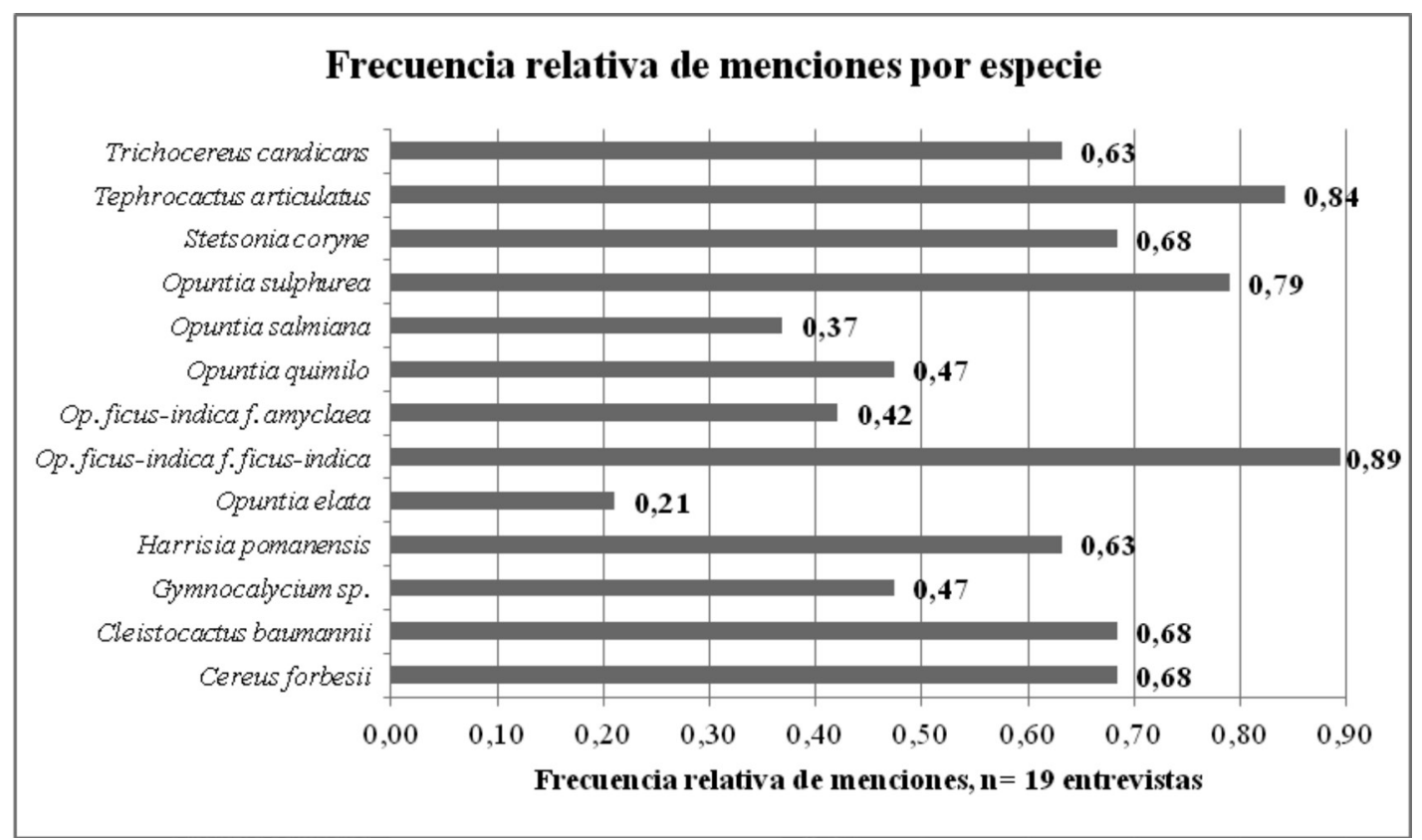

Fig. 3. Histograma de frecuencias relativas de las menciones de las especies a partir del registro fotográfico. 


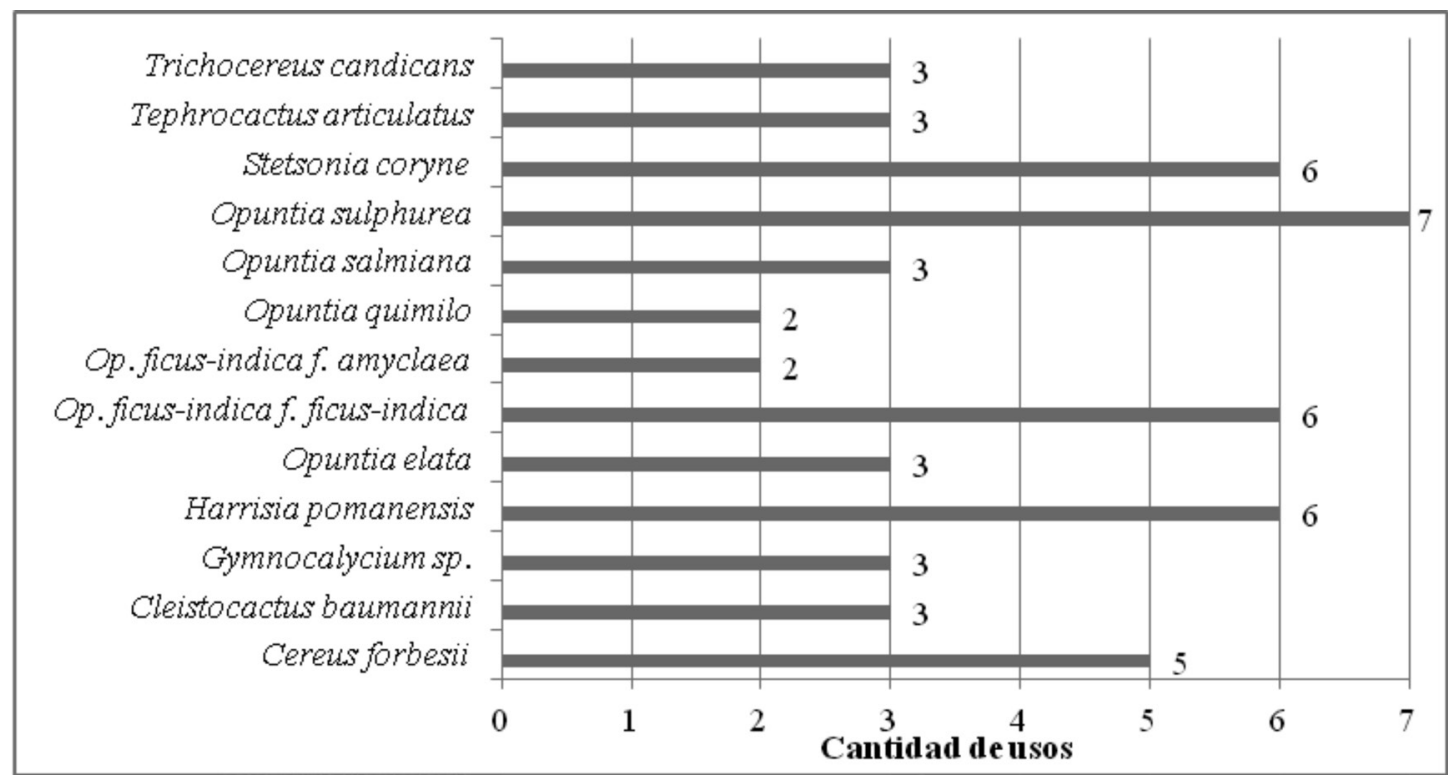

Fig. 4. Histograma de frecuencias absolutas de la cantidad de usos por especie.

Cabe destacar para "pasacana" (Trichocereus candicans) la referencia como predictiva del clima, el $32 \%$ de los entrevistados mencionaron que la floración de estas plantas indican la venida de las lluvias: "Si florece, a los dos días sabes que llueve, la tenemos en cuenta siempre".

Se registraron todas las prácticas de manejo consideradas, siendo algunas más comunes que otras, como es el caso de la recolección para todas las especies que tienen algún órgano útil y que son importantes para la subsistencia (Fig. 5). La tolerancia y el trasplante son las prácticas que presentan mayor cantidad de menciones, y la siembra y plantación sólo se aplica a las especies que han sido históricamente parte de la agricultura regional.

La recolección es una de las prácticas de manejo más generalizada, por lo común se realiza con fines forrajeros, alimentarios, y a veces ornamentales. Consiste en recolectar de los ambientes naturales artejos, frutos, flores y/o brotes; con diferentes herramientas, como hachas, machetes o cuchillos.

La tolerancia se realiza en todas las especies estudiadas, es la práctica más mencionada y casualmente casi nunca con fines ornamentales. Se caracteriza porque a la hora de limpiar un campo se permite la presencia de un individuo, optándose por su no remoción.

El fomento o inducción, se realiza sólo con fines ornamentales, en 12 de los 13 taxones considerados en este estudio. Consiste en la reproducción vegetativa mediante artejos o ramificaciones, con el fin de aumentar la cantidad de individuos.

La protección fue la práctica que menor cantidad de personas mencionan llevar adelante. Involucra no sólo la intención de aumentar la cantidad de individuos sino el esfuerzo y energía invertidos en el cuidado de las plantas, ya sea cuidando la tierra o regándolas.

La siembra y plantación se mencionó sólo para 6 especies, requiere de un gasto de energía extra, con técnicas específicas y una elevada intervención humana. Los modelos que se siguen son dos, uno para cactáceas columnares, como es el caso del Stetsonia coryne: se corta una rama de $20-40 \mathrm{~cm}$ de largo, se la planta de manera perpendicular a la línea de cerco con una distancia de 50-100 cm entre individuos; el otro modelo para las especies de Opuntia, por ejemplo, Opuntia ficus-indica f. ficus-indica, en que se suelen plantar los artejos, o una parte de estos, de forma horizontal o vertical. 


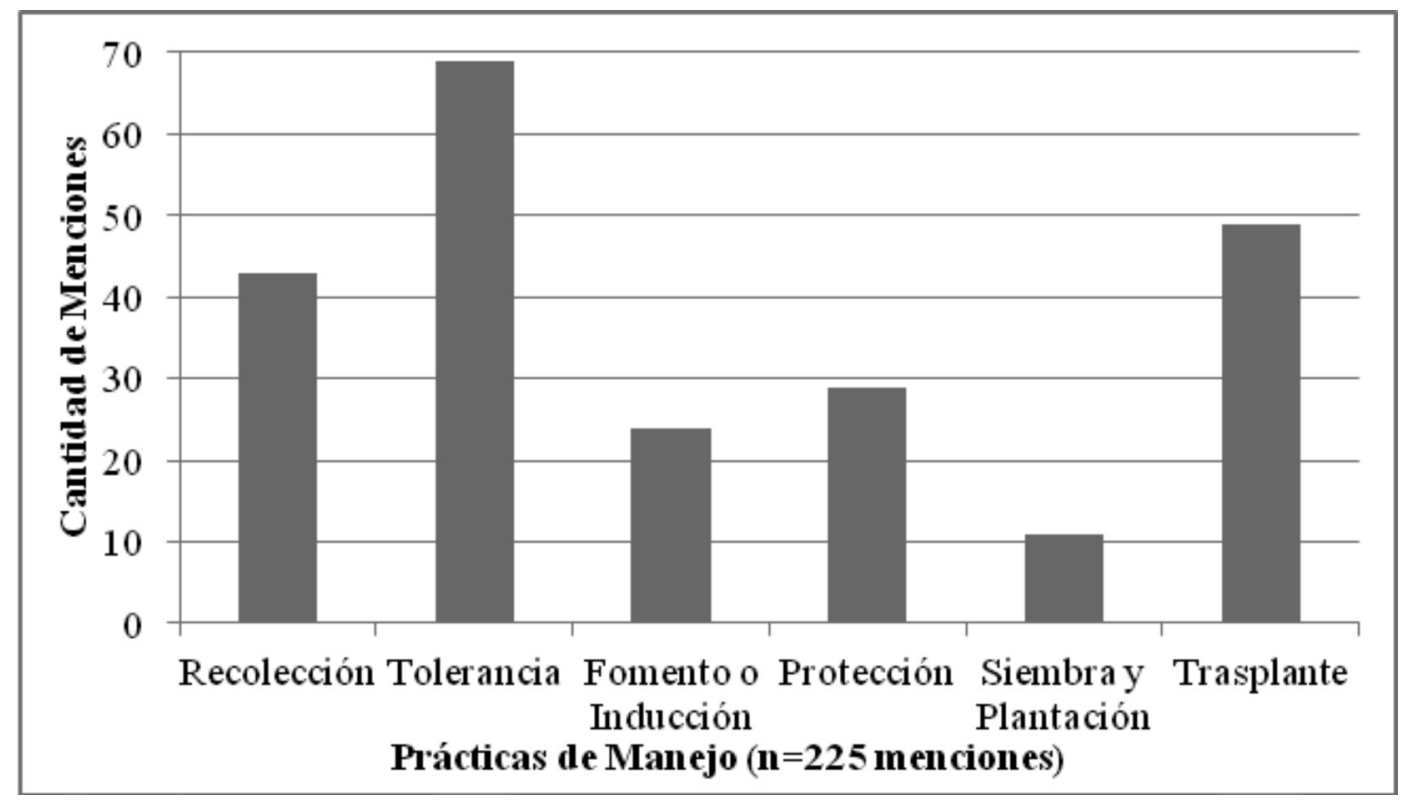

Fig. 5. Histograma de frecuencias absolutas de la cantidad de menciones por práctica de manejo.

El trasplante se realiza en todas las especies relevadas, es muy común entre los entrevistados, quienes mencionan que en cualquier momento, cuando están fuera de su ciudad o en el "monte", pueden sacar un individuo y llevarlo a su campo/casa. Es una práctica circunstancial y está ligada al encuentro de determinadas especies. A partir del test de Lickert, de las 19 encuestas realizadas, 4 personas valoraron a las especies de Cactaceae como "Muy importantes", 13 como "Importantes" y sólo 2 como "Poco importantes". Siendo la Moda el valor "Importante". Sin embargo, en el discurso, muchos informantes comentaron la dificultad de optar entre "Importante" y "Muy Importante", y que para ellos no existía tal diferencia.

Los aspectos más relevantes mencionados por los pobladores locales son:

Las especies de Cactaceae para los ganaderos criollos o campesinos son muy valoradas, en especial las que tienen usos forrajeros o alimentarios, dado que son recursos de subsistencia para el ganado en la época desfavorable, como el invierno, cuando otras forrajeras escasean.

Varios entrevistados destacaron que durante el trabajo bajo el sol, las cactáceas son consideradas como un recurso hídrico (para saciar la sed) y que, por esto, tienen un valor muy importante.

En las zonas más urbanizadas también son valorados estéticamente por su morfología, sea para embellecer las casas y/o jardines, o para la venta como ornamentales.

Entre los comentarios sobre Cactaceae se incluyen: "Son malos porque lastiman a los animales, pero es sólo por el puqui, y muy buenos porque brindan alimento, forraje y se aguantan el clima, y son las que sobreviven en las peores épocas", "son valiosos, porque tienen agua y son duros, no se mueren", “en época de crisis, los usas son los que te salvan las papas", "útiles porque cuando hay sequía es lo que te ayuda a salir del invierno como con el cardón", "muy interesantes y muy bellos por eso los colecciono", "flores hermosas, yo las tengo para atraer aves".

\section{Discusión y Conclusiones}

Los informantes entrevistados reconocieron y brindaron nombres vernáculos de 11 
especies nativas y 2 variedades de una especie naturalizada de cactáceas, además de aportar información sobre usos y prácticas de manejo. El reconocimiento de estas 12 especies representa el $54 \%$ de las cactáceas que crecen en la zona de estudio, con usos principales como plantas forrajeras y alimenticias, siendo un porcentaje mayor al encontrado en estudios etnobotánicos realizados con comunidades rurales de la cuenca del Río Bermejo, en Salta, por Hilgert \& Kiesling (2002). Estos autores señalan el reconocimiento de 7 especies por los pobladores locales, que representan el 37\% de las cactáceas usadas como alimenticias y medicinales.

Sobre las especies que no fueron reconocidas o mencionadas, es importante destacar que algunas poseen una distribución muy restringida y se encuentran en poca abundancia; en otros casos, las especies son clasificadas por los pobladores locales en grandes grupos, como las denominadas "bochitas", que incluyen individuos de distintos géneros, como Echinopsis, Gymnocalycium, Parodia y Acanthocalycium, lo que refleja un agrupamiento por su forma de vida, resultado similar al presentado por Scarpa (2012) sobre etnoclasificación de plantas por pobladores criollos del noroeste de la Argentina, que identifican como "pencas" a todos los representantes locales de las familias botánicas Cactaceae y Crassulaceae.

En el caso del género Gymnocalycium, los informantes no discriminaron las diferentes especies botánicas que se encuentran en su ambiente, con excepción de una de ellas, dado que sus características morfológicas hacen muy difícil establecer características propias de cada una. Esta dificultad también se registra entre los especialistas botánicos, dado que no existe un acuerdo general sobre la cantidad de especies incluidas dentro de este género (Demaio \& Trevisson, 2006). La única especie del género que los informantes discriminan es Gymnocalycium schickendantzii (F. A. C. Weber) Britton \& Rose, en La Batea, en la unidad fisiográfica de Salinas Grandes, donde es muy abundante. Los encuestados de esa unidad la denominan "churrete", y no reconocían ninguna de las otras especies del área, sugiriendo que es posible que este nombre vernáculo sea propio para esta especie en particular.

Opuntia ficus-indica f. ficus-indica es un caso particular, porque es una especie naturalizada que no se encontró en los relevamientos de la vegetación cercana a las viviendas, que crece en los ambientes domésticos y ha sido relacionada con los seres humanos y la producción agrícola desde hace varios siglos (Kiesling, 1998). Es la especie más reconocida, el $79 \%$ de las personas mencionaron tener conocimiento de algún uso y en este estudio se registraron 6 tipos diferentes de usos. Como forrajera, se citó que se utiliza toda la planta, concordando con Kiesling (1998) y otros estudios (Arenas, 2003; Hilgert \& Kiesling, 2002; Kiesling, 2001; Le Houérou, 1996). Opuntia ficusindica f. ficus-indica es una de las cactáceas que tiene la mayor importancia agronómica, tanto por sus sabrosos frutos como por sus tallos que sirven de forraje o son comestibles, consumidos como verdura. Además, es uno de los taxones que presenta la mayor cantidad de usos (forrajero, alimentario, medicinal, purificador del agua, cosmético, ornamental) lo que aumenta su importancia como recurso natural (Zapata et al., 2005). También, Sáenz \& Berger (2006) indican que al mucílago de las "palas" de Opuntia ficus-indica f. ficus-indica se le atribuye la capacidad de purificar el agua y de servir para fijar pinturas.

En este estudio se registraron usos para todos los taxones revelados; para algunos, más de uno. El uso que se destaca es el forrajero, señalado fundamentalmente por informantes criollos y ganaderos: "las especies espinosas se las damos al ganado después de haber chamuscado las pencas...sino le damos los frutos maduros". Las 8 especies consideradas forrajeras en este trabajo también presentan menciones para este uso en estudios etnobotánicos en la Argentina: Arenas (2003); Arenas \& Scarpa (1998); Hilgert \& Kiesling (2002); Kiesling (2001); Scarpa (2007); Trillo (2010) y Zapata et al. (2005). Este uso es de vital importancia en la zona de estudio, considerando sus características climáticas poco favorables; por esta razón se destacan las especies de Cactaceae que persisten durante cualquier época del año y ciclo sequía humedad, cuando los otros vegetales forrajeros 
convencionales escasean (Demaio \& Trevisson, 2006; Le Houérou, 1996; Trillo, 2010).

En el presente estudio el uso alimentario se menciona para la mayoría de las especies, dado que las cactáceas se caracterizan por tener frutos jugosos, por lo común sabrosos, como se ha indicado asimismo en estudios similares realizados en otras comunidades: Arenas (2003); Demaio \& Trevisson (2006); Hilgert \& Kiesling (2002); Kiesling (2001); Le Houérou (1996). Además de su utilización como comestibles, las cactáceas son consumidas como recurso hídrico, y resultan de gran importancia para las condiciones climáticas en la que viven los informantes. A este respecto, Arenas (2003), sostiene que para las comunidades Wichi y Toba las fuentes de agua y las especies botánicas con capacidad de acumulación de agua son muy preciadas y forman parte del conocimiento botánico de las comunidades.

Para la construcción de cercos, se destaca el uso de Stetsonia coryne, especie mencionada para tal fin por Arenas \& Scarpa (1998). La construcción de estos "cercos vivos" es una técnica muy antigua, registrada desde tiempos prehispánicos, donde estos cercos se utilizaban principalmente para la defensa, y que ahora persisten como cercados del hogar (Le Houérou, 1996; Pastor et al., 2012). Es una práctica muy especializada y refinada para cumplir un fin fijo y que implica mucho esfuerzo (Arenas \& Scarpa, 1998; Casas et al., 2002). En este trabajo se encontraron varias especies utilizadas para la construcción de cercos vivos, como Opuntia sulphurea, Opuntia ficus-indica f. amyclaea, Harrisia pomanensis, Cleistocactus baumannii y Opuntia elata, sin tanta inversión de energía o especificidad.

Con respecto al uso tintóreo, se destaca la mención a Opuntia sulphurea como tintórea, tanto por sus artejos como por la "peste" que albergan. Esto último se refiere a la capacidad de mantener un parásito que permite extraer el colorante, Dactylopius sp., la "cochinilla" (Trillo et al., 2007).

En el uso ornamental se incluyen dos aspectos diferentes: las plantas ornamentales según un criterio estético, que cumplen la función de adornar y embellecer el ámbito doméstico (Albuquerque et al., 2005); y las plantas ornamentales que se utilizan con fines comerciales, es decir, que tienen un valor económico importante (Reyes-García et al., 2006). Estudios realizados en la provincia de Misiones sobre la comercialización de especies nativas (Pochettino, 2007) hacen evidente que el conocimiento local es necesario para identificar y localizar plantas ornamentales, así como para realizar la recolección y reproducción de individuos que se consideraban localmente más convenientes, mediante las técnicas más apropiadas. De manera similar en nuestro estudio las especies con valor para la comercialización (11 especies) son ampliamente reconocidas y valoradas por los informantes, reflejando así la importancia del conocimiento etnobotánico local. Por otro lado, coincidiendo con Pochettino (2007), entendemos como tarea futura en lo referido a la comercialización de cactáceas, evaluar la sustentabilidad de las actividades insertas en nuevos contextos regulados por las condiciones de mercado, considerando el hecho de que, la mayoría de las veces, las prácticas se basan en la recolección de individuos del monte sin reposición, lo que podría generar una disminución del tamaño de las poblaciones silvestres.

En relación con la comercialización de especies nativas como plantas ornamentales, concordando con Cardini (2005), la economía de mercado tiene un rol importante en el proceso de globalización, y se hace necesario comprender que existen múltiples consideraciones en el producto que sale a la venta: se trate como "obra de arte", como "reivindicación identitaria", como portador de un sentido histórico o como mercancía o alternativa económica. De acuerdo con Martínez (2012), la venta de artesanías y la revalorización de la flora nativa podrían constituir una "estrategia de resistencia", una expresión de la interdependencia entre lo material y lo simbólico, donde lo económico y lo cultural se entremezclan en la vida social y comunitaria. Se destaca que a pesar de que quienes compran los productos resignifican el valor cultural estético que se le dio originalmente, existe el riesgo de la homogenización y el reduccionismo de lo 
étnico a lo típico, como destacaba García Canclini (1982). Sin embargo, en coincidencia con Martínez (2012), "las necesidades del mercado comienzan a incluir los bienes simbólicos tradicionales de las comunidades... en un proceso en el que estos pueblos ven en sus productos una posibilidad de elevar sus ingresos monetarios y de escapar a estructuras económicas más opresoras". Se rescata ese sentido emocional y de elevado valor por lo nativo y propio de nuestro territorio.

Algunos usos hacen referencia a épocas pasadas o prácticas que ya no se observan, como la purificación del agua y la fijación de pintura con el mucílago de Opuntia ficusindica f. ficus-indica, como mencionan Dos Santos et al. (2009) y Zapata et al. (2005). Este abandono de prácticas y usos responde a múltiples razones, dentro de las que se destacan la pérdida de la biodiversidad, como proponen Arias Toledo et al. (2010), quienes abordan la problemática de la restricción del uso de plantas medicinales nativas por la disminución en el acceso a parches boscosos, y/o por la globalización tecnológica producto del progreso económico, destacada por el trabajo de Muiño (2012) que analiza la disminución en la producción de alimentos en huertas y jardines en la actualidad.

En relación a las prácticas de manejo, en cuanto a la cantidad de menciones obtenidas en este trabajo, la práctica que presenta más menciones es la tolerancia (69 menciones de un total de 225). A diferencia de otros trabajos (Blancas et al., 2010; Caballero et al., 1998; Casas et al., 1999, 2002; Lira et al., 2009), en este caso resultó ser una práctica mucho más común que la de recolección. Se presume que puede deberse al hecho de que no exige inversión de energía como en el caso de la recolección (ir hasta el monte, buscar lo que se necesita y transportarlo hasta el hogar) sino que prácticamente no requiere de esfuerzo (sólo se dejan los individuos donde se encuentran). Sin embargo, requiere de la decisión de no sacar determinados individuos y dejarlos en ese ambiente manipulado y moldeado por las personas, como proponen Caballero et al. (1998) y Casas et al. (1996, 1999).

El trasplante fue la segunda práctica, en orden descendente, según cantidad de menciones (49 en total). Caballero et al. (1998) sugieren que esta práctica se realiza cuando existe un valor implícito en determinada especie para una persona, y resulta mucho más sencillo realizar un trasplante que una práctica como la siembra y plantación, que requiere mucho más conocimiento sobre la especie y su reproducción, e implica un gasto de energía mayor (Casas et al., 1996). Como señalan Demaio \& Trevisson (2006) y Kiesling (1998), esta práctica se ve beneficiada cuando se trata de cactáceas, que se reproducen más fácilmente de manera vegetativa, lo que implica que con trasplantar sólo un artejo es posible mantener un individuo que sobreviva en cualquier lado, sin mucho esfuerzo ni conocimiento.

La recolección fue una práctica mencionada en 43 oportunidades para la mayoría de los taxones (excepto Opuntia elata), por parte de todos los pobladores, reflejando que es una conducta muy instalada en las comunidades en estudio. Como destacan en sus trabajos Caballero et al. (1998), Casas (2001), Casas et al. (1996, 1999), la recolección no sólo es una de las prácticas más comunes y realizadas en todo el mundo, sino que también es la más antigua, desde comunidades de cazadores y recolectores, por lo que no resulta extraño que presente la mayor cantidad de menciones.

En el caso del fomento o inducción, esta práctica fue desarrollada por los pobladores del noroeste de Córdoba con plantas para fines ornamentales, en especial para la comercialización. Al respecto, Casas et al. (1996) señala que existe un valor implícito en la familia Cactaceae que la convierte en un recurso económico valioso, por lo que explica la intención de reproducir e incrementar el número de individuos. La protección, en cambio, involucra el cuidado de las especies (protección contra herbívoros, disminución de plantas competidoras, agregado de tutores, entre otras actividades) por lo que realiza un esfuerzo para aumentar la supervivencia de los individuos seleccionados como buenos ejemplares. En este estudio, la protección tuvo más menciones que el fomento, y para mayor cantidad de usos (forrajeros, alimentarios, para construcción de cercos y otros) reflejando la intencionalidad de mantener individuos de ciertas especies para satisfacer necesidades 
locales. Como proponen Caballero et al. (1998) existe un sistema de prácticas de "manipulación de especies silvestres que dan lugar a un complejo paisaje antropogénico donde prácticamente todos sus elementos tienen algún papel en la economía local y son, en alguna medida, el resultado de un prolongado y cuidadoso proceso de selección y manipulación por los seres humanos".

Por último, la siembra y plantación es la práctica menos relevada, y para el menor número de especies (6). Esto se explicaría por el escaso número de pobladores que poseen la disponibilidad de tiempo, mano de obra y conocimientos y experiencias específicos para desarrollar esta tarea. Así como otros autores destacan que la siembra y plantación es una práctica no sólo mucho más avanzada, en lo que respecta a la inversión de energía por parte de las personas, sino que implica una relación mucho más estrecha y fuerte con estas especies que tienen elevado valor para las personas que las usan (Carmona \& Casas, 2005; Casas et al., 1996, 1999, 2002; Krapovickas, 2011).

Por otro lado, cabe mencionar el trabajo de Dos Santos et al. (2009), que realizan una clasificación diferente de las prácticas de manejo. Proponen un modelo respecto de una especie en particular, que ha sido mencionada con varias formas de manejo y, como criterio, se clasifica a las personas como "mantenedores" (que sólo mantienen la planta o que la tienen en su patio), "manejadores" (con alguna intervención sobre la planta), "cultivadores" y "usadores" (que sólo usan las plantas, como en la recolección). Resulta interesante observar que se focaliza en las personas y no en las especies ni en las prácticas, lo que permitiría visualizar mejor las habilidades o destrezas de las personas, lo que es clave para estudiar lo referido a la manipulación del ambiente. Según esta clasificación, ninguno de nuestros entrevistados resulta un "usador" (porque ninguno realiza solamente la recolección) y, si analizamos a Stetsonia coryne, sólo 3 personas fácilmente se identifican como "cultivadores".

Lavaloración dela familiabotánica Cactaceae por parte de las personas entrevistadas, en términos generales, es alta, con niveles de "Importante" o "Muy Importante", debido a su potencial como plantas ornamentales (uso estético o comercial), en concordancia con Casas et al. (1999) y Kiesling (1998); o bien, debido a su utilidad para el quehacer y el desarrollo de la vida diaria: usos forrajero, alimentario, construcción de cercos, entre otros (González-Insuasti \& Caballero, 2007; Thomas et al., 2009a, b; Trillo, 2010).

En el presente trabajo los pobladores expresaron una alta valoración de las cactáceas, dado que para ellos representa un recurso de subsistencia en su ambiente con escasez de agua, debido a sus características y potencialidades. Los motivos de esta apreciación se basan en la cantidad de agua que conservan en sus tejidos y su calidad como fuente alimentaria y forrajera, que presentan la mayoría de los integrantes de la familia.

Por último, existen 13 taxones nativos y naturalizados de Cactaceae que han sido reconocidos y nombrados por los pobladores locales, y que presentan usos y prácticas de manejo en localidades rurales de ambientes áridos que forman parte de economías marginales. El registro de 12 usos diferentes y 6 prácticas de manejo para los miembros de esta familia, que actualmente se encuentran activas, son una evidencia de la importancia del conocimiento botánico local sobre las cactáceas para la subsistencia y el desarrollo de las actividades económicas de los pobladores.

Esto se refleja en una alta valoración de la familia Cactaceae, en particular por su utilidad como forrajeras y alimenticias para los pobladores (pequeños ganaderos), y por su valor estético y económico. El estudio de estos recursos, naturales y culturales en conjunto, contiene información útil para todos los pobladores, y para los encargados de la realización de planes de manejo y conservación de los ambientes áridos.

\section{Agradecimientos}

Expresamos nuestro agradecimiento a todos los pobladores rurales y urbanos de las localidades del noroeste de Córdoba que nos brindaron desinteresadamente la información etnográfica solicitada. Además queremos agradecer el asesoramiento permanente del Dr. Pablo Demaio respecto a la correcta 
identificación de todos los taxones. Por último queremos agradecer los comentarios que realizaron los evaluadores ya que con sus aportes mejoraron sustancialmente este trabajo.

\section{Bibliografía}

AGUILERA, R. M., A. DURAND-SMITH, E. M. RODRIGUEZ, \& M. ROMERO MENDOZA. 2003. Veinticinco años de investigación cualitativa en salud mental y adicciones con poblaciones ocultas. Primera parte. Salud Mental 26: 76-83.

ALBUQUERQUE, U. D., L. ANDRADE \& J. CABALLERO. 2005. Structure and floristics of homegardens in Northeastern Brazil. J. Arid Environ. 62: 491-506.

ALDRIGE, A. \& K. LAVINE. 2003. Topografía del mundo social. Teoría y práctica de la investigación mediante encuestas. Gedisa Editorial, España. 252 pp.

ALTRICHTER, M. 2006. Wild life in the life of local people of the semi-arid Argentine Chaco. Biodivers. Conserv. 15: 2719-2736.

ARENAS, P. 2003. Etnografía y Alimentación entre los Toba-Ñachilamole\#ek y Wichí-Lhuku'tas del Chaco Central (Argentina). Latin Grafica S. R. L., Buenos Aires, Argentina. 245-288 pp.

ARENAS, P. \& G. F. SCARPA. 1998. Ethnobotany of Stetsonia coryne (Cactaceae), the "cardón" of the Gran Chaco. Haseltonia 6: 41-51.

ARIAS TOLEDO, B., C. TRILLO \& M. GRILLI. 2010. Uso de plantas medicinales en relación al estado de conservación del bosque en Córdoba, Argentina. Ecol. Austral. 20: 235-246.

ARIAS TOLEDO, B., C. TRILLO, M. GRILLI. S. COLANTONIO \& L. GALETTO. 2014. Relationships between land-use types and plant species used by traditional ethno-medical system. Euro. J. Med. Plant. 4: 998-1021.

BASCO, M., P. TSAKOUNAGKJOS \& M. BORRO. 1980. Esquema conceptual y metodología para el estudio de Unidades Agropecuarias con énfasis en el minifundio. S. N E. y S. R. Ministerio de Agr. y Gan. Nación. 82 pp.

BERBERIÁN, E. 1987. Crónicas del Tucumán. Siglo XVI. Comechingonia, Córdoba. 15-89 pp.

BERKES, F. 1999. Sacred Ecology. Traditional Ecological Knowledge and Resource Management. Taylor \& Francis, Philadelphia. 209 pp.

BERNARD, H. R. 1995. Research Methods in Anthropology Qualitative and Quantitative Approaches. Altamira Press, UEA. 821 pp.

BIURRUN, E., L. GALETTO, A. M. ANTON \& F. BIURRUN. 2007. Plantas silvestres comestibles utilizadas en poblaciones rurales de la Provincia de
La Rioja (Argentina). Kurtziana 33: 121-140.

BLANCAS, J., A. CASAS, S. RANGEL-LANDA, A. MORENO-CALLES, I. TORRES, E. PÉREZNEGRÓN \& P. DÁVILA. 2010. Plant Management in the Tehuacán-Cuicatlán Valley, Mexico1. Econ. Bot. 64: 287-302.

CABAllero, J. \& L. CORTÉS. 2001. Percepción, uso y manejo tradicional de los recursos vegetales en México. En B. Rendón Aguilar, S. Rebollar Domínguez, J. Caballero \& M. A. Martínez Alfaro (eds.), Plantas, Cultura y Sociedad, pp. 79-100. Universidad Autónoma Metropolitana, México. 317 pp.

CABAllero, J., A. CASAS, L. CORTÉS \& C. MAPES. 1998. Patrones en el conocimiento, uso y manejo de plantas en pueblos indígenas de México. Estudios Atacameños 16: 181-196.

CABIDO, M. \& M. ZAK. 1999. Vegetación del Norte de Córdoba. Secretaría de Agricultura, Ganadería y Recursos Renovables de la provincia de Córdoba y Agencia Córdoba Ambiente, Córdoba. 112 pp.

CABIDO, M. \& M. J. PACHA. 2002. Vegetación y Flora de la Reserva Natural Chancaní. Publicaciones Técnicas serie C. Agencia Córdoba Ambiente, Córdoba. 95 pp.

CABRERA, A. 1976. Regiones fitogeográficas argentinas. En Enciclopedia Argentina de Agricultura y Jardinería 2, 1. Editorial ACME, Argentina. 85 pp.

CAPPARELLI, A. \& R. RAFFINO. 1997. La etnobotánica de "El Sinchal" (Catamarca) y su importancia para la arqueología I: Recursos combustibles y madereros. Parodiana 10: 181-188.

CÁCERES, D., F. SILVETTI, G. FERRER \& G. SOTO. 2006. "Y... vivimos de las cabras". Transformaciones sociales y tecnológicas de la Capricultura. Editorial La Colmena. Buenos Aires, Argentina. 269 pp.

CARDINI, L. 2005. Las" puestas en valor" de las artesanías en Rosario: pistas sobre su" aparición" patrimonial. Cuadernos de antropología social 21: 91-109.

CARMONA, A. \& A. CASAS. 2005. Management, phenotypic patterns and domestication of Polaskia chichipe (Cactaceae) in the Tehuacán Valley, Central Mexico. J. Arid Environ. 60: 115-132.

CASAS, A. 2001. Silvicultura y Domesticación de plantas en Mesoamérica. En B. Rendón Aguilar, S. Rebollar Domínguez, J. Caballero \& M. A. Martínez Alfaro (eds.), Plantas, Cultura y Sociedad, pp. 123157. Universidad Autónoma Metropolitana, México.

CASAS, A., J. L. VIVEROS, E. KATZ \& J. CABALLERO. 1987. Las plantas en la alimentación mixteca: una aproximación etnobotánica. Am. Indíg. 47: 317-343.

CASAS, A., M. C. VÁZQUEZ, J. L. VIVEROS \& J. CABALLERO. 1996. Plant management among the Nahua and the Mixtec from the Balsas River Basin: and ethnobotanical approach to the study of plant domestication. Hum. Ecol. 24: 455-478. 
CASAS, A., J. CABALLERO, A. VALIENTE-BANUET, J. A. SORIANO \& P. DÁVILA. 1999. Morphological variation and the process of domestication of Stenocereus stellatus (Cactaceae) in Central Mexico. Am. J. Bot. 86: 522-533.

CASAS, A.,A. VALIENTE-BANUET \& J. CABALLERO. 2002. Evolutionary trends in columnar cacti under domestication in south-central Mexico. In Fleming, T. H., \& A. Valiente-Banuet (eds.), Columnar cacti and their mutualists: evolution, ecology, and conservation. 137-164 pp. University of Arizona Press, Tucson, AZ.

CASAS, A., A. OTERO-ARNAIZ, E. PÉREZNEGRÓN \& A. VALIENTE-BANUET. 2007. In situ management and domestication of plants in Mesoamerica. Ann. Bot. 100: 1101-1115.

COSTA-NETO, E. M. 2002. Metodología de la Investigación Etnoentomológica. En Manual de Etnoentomología. 77-87 pp. Ed. Zaragoza. M\&TManuales \& Tesis SEA.

COTTON, C. M. 1996. Ethnobotany: principles and applications. John Wiley \& Sons, New York, USA. 424 pp.

CUNNINGHAM, A. B. 2001. Etnobotánica aplicada: pueblos, usos de plantas silvestres y conservación. Nordan-WWF-UNESCO, Montevideo. 310 pp.

DEMAIO, P. \& M. TREVISSON. 2006. Cactus de Córdoba y el centro de Argentina. Editorial L.O.L.A. Literature of Latin America. Buenos Aires, Argentina. $78 \mathrm{pp}$.

DOS SANTOS, K. L., N. PERONI, R. P. GURIES \& R. O. NODARI. 2009. Traditional knowledge and management of Feijoa (Acca sellowiana) in southern Brazil. Econ. Bot. 63: 204-214.

GARCÍA CANCLINI, N. 1982. Las culturas populares en el capitalismo. Ediciones Casa de las Américas. YG, EL vedado, Ciudad de La Habana, Cuba. 224 pp.

GONZÁlEZ-INSUASTI, M. S. \& J. CABALLERO. 2007. Managing plant resources: How intensive can it be? Hum. Ecol. 35: 303-314.

HILGERT, N. \& R. KIESLING. 2002. The utilization of cacti in the upper Rio Bermejo Basin, Salta, Argentina. Haseltonia 9: 41-50.

INSTITUTO DE BOTÁNICA DARWINION. Base de datos electrónica. Disponible: <http://www.darwin. edu.ar/> [Consulta: 30-I-2015].

KIESLING, R. 1998. Origen, domesticación y distribución de Opuntia ficus-indica. J. Prof. Assoc. Cactus 3: 5059.

KIESLING, R. 2001. Cactáceas de la Argentina promisorias agronómicamente. J. Prof. Assoc. Cactus 4: 11-15.

KIESLING, R. \& O. E. FERRARI. 2005. 100 cactus Argentinos. Editorial Albatros Saci. Buenos Aires, Argentina. $128 \mathrm{pp}$.

KIESLING, R., M. SARAVIA, L. OAKLEY, N. MURUAGA, D. METZING \& L. NOVARA. 2012. Cactaceae Juss. Flora el Valle de Lerma. Aportes
Botánicos de Salta - Ser. Flora. Herbario MCNS. Facultad de Ciencias Naturales de Salta. Salta, Argentina. $142 \mathrm{pp}$.

KRAPOVICKAS, A. 2011. Sembrar, Plantar, Cultivar, Domesticar. Bonplandia 20: 419-426.

LE HOUÉROU, H. N. 1996. The role of cacti (Opuntia $\mathrm{sp}$ ) in erosion control, land reclamation, rehabilitation and agricultural development in the Mediterranean Basin. J. Arid Environ. 33: 135-159.

LIRA, R., A. CASAS, R. ROSAS-LÓPEZ, M. PAREDESFLORES, E. PÉREZ-NEGRÓN, S. RANGELLANDA, L. SOLÍS, I. TORRES \& P. DÁVILA. 2009. Traditional knowledge and useful plant richness in the Tehuacán-Cuicatlán valley, Mexico. Econ. Bot. 63: 271-287.

LUTI, R., M. A. B. SOLIS, F. M. GALERA, N. MÜLLER, M. BERZAL, M. NORES, M. A. HERRERA \& J. C. BARRERA. 1979. Vegetación. En J. B. Vázquez, R. A. Miatello \& M. E. Roqué. (eds.), Geografía Física de la Provincia de Córdoba, 297-368 pp. Ed. Boldt, Buenos Aires, Argentina.

MARTÍNEZ, G. J. 2012. Recolección, disponibilidad y uso de plantas en la actividad artesanal de comunidades tobas (qom) de Chaco Central (Argentina). En P. Arenas (ed.), Etnobotánica en zonas áridas y semiáridas del Cono Sur de Sudamérica, 195-224 pp. CEFYBO-CONICET, Buenos Aires, Argentina.

MARTÍNEZ-CROVETTO, R. 1964. Estudios etnobotánicos. I. Nombres de plantas y su utilidad, según los indios tobas del este del chaco. Bonplandia 1: 279-333.

MORELLO, J. H., A. F. RODRÍGUEZ \& W. PENGUE. 2009. Análisis descriptivo del proceso de desmonte y habilitación de tierras en el Chaco Argentino. En J. H. Morello \& A. F. Rodríguez (eds.), El Chaco sin Bosques: la Pampa o el desierto del futuro, 291312 pp. Orientación Gráfica Editores, Buenos Aires, Argentina.

MUIÑO, W. 2012. Los "puestos" del oeste pampeano. La relación de los campesinos criollos con las plantas a través de los huertos y jardines. En P. Arenas (ed.), Etnobotánica en zonas áridas y semiáridas del Cono Sur de Sudamérica, 225-250 pp. CEFYBOCONICET, Buenos Aires, Argentina.

PADUA, J. 1994. Técnicas de investigación aplicadas a las ciencias sociales. Sección de Obras de Sociología, Fondo de Cultura Económica Chile S. A. 360 pp.

PASTOR, S., M. MEDINA, A. RECALDE, L. LÓPEZ \& E. BERBERIÁN. 2012. Arqueología de la región montañosa central de Argentina. Avances en el conocimiento de la historia Prehispánica tardía. Relaciones de la Sociedad Argentina de Antropología XXXVII 1: 89-112.

POCHETTINO, M. L. 2007. Recolección y comercialización de plantas silvestres en dos comunidades Mbya-Guaraní (Misiones, Argentina). Kurtziana 33: 27-38. 
POCHETTINO, M. L., P. M. ARENAS, D. SÁNCHEZ \& R. CORREA. 2008. Conocimiento botánico tradicional, circulación comercial y consumo de plantas medicinales en un área urbana de Argentina. Bol. Latinoam. Caribe Plant. Med. Aromat. 7: 141-148.

REYES-GARCÍA, V., T. HUANCA, V. VADEZ, W. LEONARD \& D. WILKIE. 2006. Cultural, practical, and economic value of wild plants: a quantitative study in the Bolivian Amazon. Econ. Bot. 60: 62-74.

ROIG, F. A. \& J. R. BÁRCENA. 1983. Tephrocactus andicola (Cactaceae), recurso alimenticio de aborígenes pre y posthispánicos de Mendoza, Argentina. Parodiana 2: 59-66.

SÁENZ, C. \& H. BERGER. 2006. Utilización agroindustrial del nopal. Food \& Agriculture Org., Roma. 168 pp.

SCARPA, G. F. 2007. Etnobotánica de los Criollos del oeste de Formosa: Conocimiento tradicional, valoración y manejo de plantas forrajeras. Kurtziana 33: 153-174.

SCARPA, G. F. 2012. "Palos, yuyos, pencas, bejucos y pastos": Los nombres de las plantas y su clasificación etnobotánica taxonómica por los criollos del Chaco semiárido norte (NE Salta - W Formosa, Argentina). En P. Arenas, Etnobotánica en zonas áridas y semiáridas del Cono Sur de Sudamérica, 117-144 pp. CEFYBO-CONICET, Buenos Aires, Argentina.

THOMAS, E., I. VANDEBROEK, P. VAN DAMME,
P. GOETGHEBEUR, D. DOUTERLUNGNE, S. SANCA \& S. ARRAZOLA. 2009a. The relation between accessibility, diversity and indigenous valuation of vegetation in the Bolivian Andes. J. Arid Environ. 73: 854-861.

THOMAS, E., I. VANDEBROEK \& P. VAN DAMME. 2009b. Valuation of forests and plant species in indigenous territory and national park IsiboroSécure, Bolivia. Econ. Bot. 63: 229-241.

TRILLO, C. 2010. Valoración del bosque y conocimiento de las plantas silvestres por parte de los pobladores de las Sierras de Guasapampa, Noroeste de la Provincia de Córdoba. Tesis Doctoral, Hemeroteca de la FCEFyN-UNC.

TRILlO, C., P. DEMAIO, S. COLANTONIO \& L. GALETTO. 2007. Conocimiento actual de plantas tintóreas por los pobladores del valle de Guasapampa, provincia de Córdoba. Kurtziana 33: 65-71.

ZAK, M. R., M. CABIDO, D. CÁCERES \& S. DÍAZ. 2008. What drives accelerated land cover change in central Argentina? Synergistic consequences of climatic, socioeconomic, and technological factors. Environ. Manage. 42: 181-189.

ZAPATA, R. M., U. O. KARLIN, F. LUCERO, R. O. COIRINI \& M. KARLIN. 2005. Manejo Sustentable del Ecosistema Salinas Grandes. Manejo de los tunales. Cartilla de divulgación. Proyectos Federales de Innovación Productiva del Ministerio de Ciencia, Tecnología e Innovación Productiva. 24 pp.

Original recibido el 17 de octubre de 2014; aceptado el 6 de abril de 2015. 